\title{
Selective PDE inhibitors rolipram and sildenafil improve object retrieval performance in adult cynomolgus macaques
}

\author{
K. Rutten • J. L. Basile • J. Prickaerts • A. Blokland • \\ J. A. Vivian
}

Received: 7 March 2007 / Accepted: 23 October 2007 /Published online: 23 November 2007

(C) The Author(s) 2007

\begin{abstract}
Rationale Selective phosphodiesterase (PDE) inhibitors improve the formation of hippocampus-dependent memories in several rodent models of cognition. However, studies evaluating the effects of PDE inhibition on prefrontal cortex-dependent cognition and in monkeys are rare.

Objectives The present study investigates the effect of the PDE4 inhibitor rolipram and the PDE5 inhibitor sildenafil on object retrieval performance. Object retrieval is a prefrontal cortical-mediated task, which is likely to capture attention and response inhibition.

Materials and methods The ability to retrieve a food reward from a clear box with an open side positioned in various orientations was assessed in adult male cynomolgus monkeys (Macaca fascicularis).

Results Rolipram (0.003-0.03 mg/kg, intramuscular [i.m.]) and sildenafil ( $0.3-3 \mathrm{mg} / \mathrm{kg}$, i.m.) dose-dependently increased correct first reaches during difficult trials, reaching significance at 0.01 and $1 \mathrm{mg} / \mathrm{kg}$, respectively. For both drugs, correct reaches were increased approximately $20 \%$; that is, performance was improved from $\sim 50$ to $\sim 70 \%$ correct.
\end{abstract}

K. Rutten $(\varangle) \cdot$ J. Prickaerts

Department of Neuroscience,

School for Mental Health and Neuroscience,

Maastricht University,

Universiteitssingel 50, P.O. Box 616, 6200 MD Maastricht,

The Netherlands

e-mail: k.rutten@np.unimaas.nl

K. Rutten · J. L. Basile · J. A. Vivian

Department of Neuroscience, Roche Pharmaceuticals Palo Alto,

Palo Alto, CA, USA

J. Prickaerts $\cdot$ A. Blokland

Department of Neuropsychology and Psychopharmacology,

Maastricht University,

Maastricht, The Netherlands
Conclusions Both rolipram and sildenafil improved object retrieval performance, thus demonstrating the cognitionenhancing effects of PDE inhibition on a prefrontal task of executive function in monkeys.

Keywords Attention - Executive function .

Phosphodiesterase · PDE4 · Rolipram · PDE5 - Sildenafil .

Cognition · Cyclic AMP - Cyclic GMP - Object retrieval .

Monkey · Primate

\section{Introduction}

Second messenger cyclic nucleotides, i.e., cyclic adenosine monophosphate (cAMP) and cyclic guanosine monophosphate (cGMP), have been strongly implicated in processes of synaptic long-term potentiation (LTP; Frey et al. 1993; Zhuo et al. 1994) and have cognitionenhancing properties (Bernabeu et al. 1996; Blokland et al. 2006; Prickaerts et al. 2002a; Prickaerts et al. 2005). cAMP and cGMP are hydrolyzed by phosphodiesterase (PDE) enzymes, and inhibitors of PDEs (PDE-Is) produce cognition-enhancing effects in animal models of cognition. In this field, research has focused on PDE4 and PDE5 inhibitors (Blokland et al. 2006; Rose et al. 2005; Rutten et al. 2006) and more recently PDE2 (Boess et al. 2004; Rutten et al. 2007b) and PDE10 (Rodefer et al. 2005) inhibitors. For example, inhibition of PDE2, PDE4, and PDE5 can improve memory in the object recognition task in rodents (Boess et al. 2004; Prickaerts et al. 2004; Rutten et al. 2007b).

Moreover, the cAMP-selective PDE4-I rolipram is an effective performance enhancer in the passive avoidance task (Egawa et al. 1997; Imanishi et al. 1997), fearconditioning test (Barad et al. 1998), and radial arm maze (Zhang and O'Donnell 2000). The cGMP-selective PDE5-I 
sildenafil has been shown to enhance performance in the object recognition task, in the T-maze, and spatial plus maze (Devan et al. 2006; Devan et al. 2004; Patil et al. 2006; Prickaerts et al. 2004). In addition, sildenafil improved object recognition memory in mice (Rutten et al. 2005), and another PDE5-I, zaprinast, improved performance in a passive avoidance task in neonatal chicks (Campbell and Edwards 2006). Taken together, these results confirm the beneficial effects of PDE inhibition on cognition involving the hippocampus.

The present study assesses the effects of PDE inhibition on object retrieval (OR) performance, a task of prefrontal cognition, in monkeys. OR (also known as the detour reaching task) involves attention, response inhibition, and planning (i.e., executive function; Diamond et al. 1989). Because the prefrontal cortex is not well represented in rodents (especially the dorsolateral prefrontal cortex) and considerable debate exists on whether the rodent prefrontal cortex subserves the same behavioral functions as the primate/human prefrontal cortex (Brown and Bowman 2002; Uylings et al. 2003), tests of prefrontal functioning (i.e., executive function) are preferentially carried out in monkeys. Successful completion of the OR task requires various hypothetical steps. An animal must appreciate the contradiction between visual and tactile input, ignore the incorrect input, remember the previous incorrect approach, and formulate a novel approach to obtain the reward, which acts against the innate tendency of perseveration toward sustained sensory stimulation (Lipina and Colombo 2001). Direct support for the involvement of the frontal cortex in OR comes from studies in which lesions of the frontal cortex impaired, while lesions of the hippocampus did not impair, performance in the task (Diamond et al. 1989; Wilkinson et al. 1997). Furthermore, deficits in OR tasks have been documented in monkeys after treatment with methylphenyl tetrahydropyridine (Schneider and Roeltgen 1993; Taylor et al. 1990a; Taylor et al. 1990b), phencyclidine (Jentsch et al. 2000; Jentsch et al. 1999a; Jentsch et al. 1999b), and after excitotoxic lesioning with quinolinic acid of the striatum (Roitberg et al. 2002). The effect of PDE-Is in the OR task have, to our knowledge, never been evaluated before in unimpaired monkeys.

As mentioned above, improvement in hippocampusdependent memory tasks in rodents is well established through PDE inhibition. However, no evidence exists on the effects of rolipram or sildenafil on prefrontal cortexdependent tests of executive function. As the PDE4 enzyme is omnipresent throughout the brain and PDE5 is expressed in the hippocampus, cortex, and cerebellum (van Staveren et al. 2004), we hypothesized that OR performance would be improved by the PDE4 and PDE5 inhibitors rolipram and sildenafil, respectively.

\section{Materials and methods}

Subjects

Fourteen adult (age 5-12 years; weights 6-9 kg) male cynomolgus macaques (Macaca fascicularis) were housed in same-sex pairs in a colony room maintained at $21 \pm 2^{\circ} \mathrm{C}$, $40 \pm 10 \%$ humidity, and on a normal 12-h light/dark cycle (lights on at 7:00 A.M.). Food (Purina High Protein no. 5045) and water were available ad libitum. All experimental procedures were approved by the Institutional Animal Care and Use Committee of Roche Palo Alto and were in accordance with National Institutes of Health guidelines.

\section{Object retrieval task}

The OR task has been previously described by Diamond et al. (1989). Briefly, this task requires a monkey to reach into a clear acrylic box (dimensions $=5 \times 5 \times 5 \mathrm{~cm}$ ) with one open side, to retrieve a food treat (cubes of apple or pear, 1$2 \mathrm{~cm}^{2}$ ). The box was positioned in front of the monkey and outside of the home cage, with the open side facing left, right, or toward the monkey. Food treats were placed on the outer edge, inner edge, or deep within the box. A test session consisted of 17 trials with nine "easy" food retrievals (i.e., placement of the food reward on the inner or outer edges of the box or when the opening is toward the monkey) and eight "difficult" food retrievals (i.e., placement of the food reward deep within the box and the open side facing left or right, see Fig. 1). The order of presentation never varied (Table 1), there were no contingencies for incorrect reaches (i.e., monkeys typically acquired the treat after the incorrect reach) or dropped treats, and trials were terminated if there were no reaches within $3 \mathrm{~min}$. The box was cleaned diligently between trials to minimize cues that could influence the task and subsequent task performance. After an initial period ( 1 week) to acclimatize the monkeys to the apparatus and procedure, tests were conducted twice a week.

\section{Drugs}

Rolipram (0.003, 0.01, 0.03, and $0.1 \mathrm{mg} / \mathrm{kg}$; Sigma Chemicals, St Louis, MO) and sildenafil (0.3, 1, and $3 \mathrm{mg} / \mathrm{kg}$; Sequoia Research Products Limited, Pangbourne, UK) were prepared fresh daily in a suspension of $10 \%$ cremaphore $/ 90 \%$ saline and administered 30 or $60 \mathrm{~min}$ before testing, respectively. Drugs were administered via intramuscular injection (i.m.) in a volume of $0.1 \mathrm{ml} / \mathrm{kg}$. Compounds were typically administered on Tuesday and Friday each week. Weekly test sessions were comprised of a vehicle session and a drug test session. Drug administration and behavioral measurement were completed blind, 

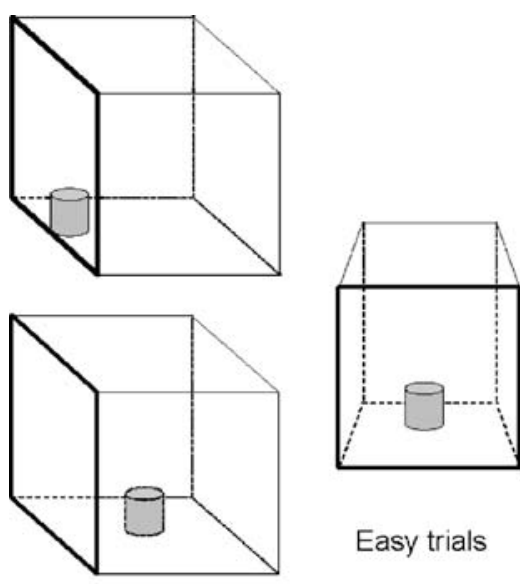

Easy trials
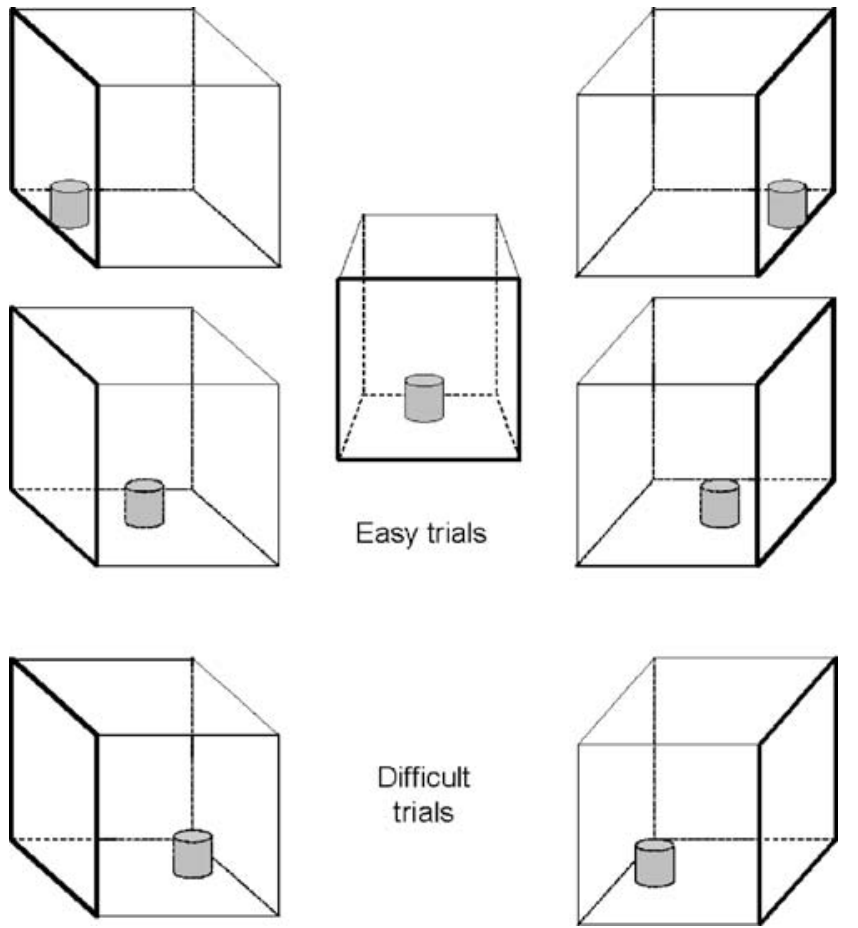

Fig. 1 A schematic overview of possible trials in the object retrieval (detour-reaching) task. The transparent box containing a food reward is depicted form the monkey's point of view. The top five orientations depict easy trials, and the bottom two orientations depict difficult trials

and each drug-dose combination was tested once. Drug doses were administered in a pseudorandom order.

Data analysis

The mean percent correct first reaches for easy and difficult food retrievals were analyzed with a one-factor (Dose) repeated-measures analysis of variance. When significant effects were demonstrated, a post-hoc Dunnett analysis comparing dose conditions to vehicle performance was performed. For all tests, the significance level was 0.05 (two-tailed).

\section{Results}

During vehicle sessions, monkeys readily reached for the food treats, successfully acquiring the treat on the first reach $100 \pm 0 \%$ during easy trials and $52 \pm 3 \%$ during difficult trials. Over the course of the experiment ( 2 months), there were no changes in vehicle performance.

The PDE4 inhibitor rolipram $(0.003-0.1 \mathrm{mg} / \mathrm{kg}$, i.m.) dose-dependently increased correct first reaches during difficult trials $(F[3,55]=13.5, p<0.05)$, reaching significance at $0.01 \mathrm{mg} / \mathrm{kg}$ (Fig. 2a). At the highest dose tested without side effects $(0.03 \mathrm{mg} / \mathrm{kg})$, the percentage correct first reaches were increased approximately 20 to $71 \pm 3 \%$.
Note that at $0.1 \mathrm{mg} / \mathrm{kg}$ (data not shown), emesis was observed in all but two monkeys; these results were therefore excluded from analysis.

The PDE5 inhibitor sildenafil ( $0.3-3 \mathrm{mg} / \mathrm{kg}$, i.m.) dosedependently increased correct first reaches during difficult trials $(F[3,50]=8.6, p<0.05)$, reaching significance at $1 \mathrm{mg} / \mathrm{kg}$ (Fig. 2b). At the highest dose tested ( $3 \mathrm{mg} / \mathrm{kg})$, correct reaches were increased approximately 20 to $73 \pm 3 \%$. No side effects were observed.

Neither rolipram nor sildenafil altered performance during the easy trials, with the exception of the high dose of rolipram $(0.1 \mathrm{mg} / \mathrm{kg})$, in which monkeys failed to perform the task (data not shown) because of emetic side effects.

\section{Discussion}

The present study demonstrates performance-enhancing effects of two selective PDE-Is on OR performance in monkeys. OR is subserved by the prefrontal cortex and/or fronto-striatal pathways, within which modulation of dopamine and acetylcholine transmission are involved in attention, response inhibition (i.e., executive function), and working memory in rodents and primates (Jentsch et al. 2000; Lipina and Colombo 2001; Palfi et al. 1996; Ramos et al. 2003; Wilkinson et al. 1997). To our knowledge, this is the first study to investigate the effects of PDE5 inhibition on executive function in monkeys. Of note, two previous studies have investigated the effects of sildenafil on cognition-related variables in humans. In these studies, sildenafil was shown to enhance simple reaction times and to some extent enhancement of focused attention (Grass et al. 2001; Schultheiss et al. 2001). However, these findings have not been further

Table 1 Primate object retrieval: trial order

\begin{tabular}{lll}
\hline Trial number & Description & Level \\
\hline 1 & LOS-line of sight & Easy \\
2 & LOS-line of sight & Easy \\
3 & RO-right outside & Easy \\
4 & RD-right deep & Difficult \\
5 & RO-right outside & Easy \\
6 & RI-right inside & Easy \\
7 & RD-right deep & Difficult \\
8 & LO-left outside & Easy \\
9 & LD-left deep & Difficult \\
10 & LO-left outside & Easy \\
11 & LI-left inside & Easy \\
12 & LD-left deep & Difficult \\
13 & LD-left deep & Difficult \\
14 & RD-right deep & Difficult \\
15 & LD-left deep & Difficult \\
16 & RD-right deep & Difficult \\
17 & LOs-line of sight & Easy \\
\hline
\end{tabular}


Fig. 2 The effects of PDE-I on object retrieval (OR) performance (mean values and SEM) a The effects of the PDE4 inhibitor rolipram and the PDE5 inhibitor sildenafil (b) on the percentage correct first reaches on difficult trials in the OR task. Asterisks indicate significant differences from baseline $(P<0.05)$
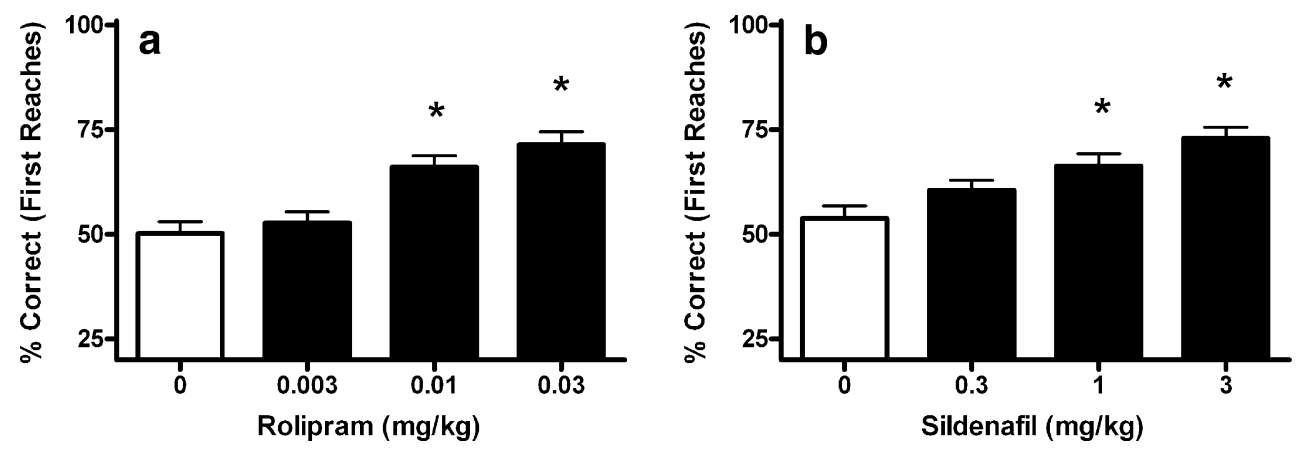

described in the literature. The effects of the PDE4 inhibitor rolipram on executive function have yet to be assessed in humans. Thus, the current results complement and extend to the cognition-enhancing effects of PDE inhibition.

Previous studies have repeatedly shown that PDE-Is can have cognition-enhancing effects, mainly in hippocampusdependent memory tasks, in rodents. For example, the PDE4 inhibitor rolipram improved long-term memory in the object recognition task, in passive avoidance learning, and fear conditioning (Barad et al. 1998; Rutten et al. 2006; Zhang et al. 2005). In addition, rolipram had performanceenhancing effects in a prefrontal cortex-dependent working memory task, i.e., delayed alternation, in young rats and young monkeys (Ramos et al. 2003). Results from the present study corroborate the cognition-enhancing effects of low-dose $(0.01 \mathrm{mg} / \mathrm{kg})$ rolipram treatment in a prefrontal cortex-dependent task, although the present OR task does not involve working memory but requires attention and response inhibition (i.e., executive function; Diamond et al. 1989). Furthermore, in aged mice, rolipram ameliorated the age-related deficits in the passive avoidance task, a test of hippocampus-dependent memory. In contrast, rolipram impaired prefrontal cortex-dependent working memory performance in aged rodents and aged monkeys. With advancing age, opposite profiles between the function of protein kinase A (PKA) in the hippocampus and prefrontal cortex were suggested to explain these results; that is, the prefrontal cortex showed indices of increased PKA activity, while the hippocampus exhibited evidence of decreased PKA activity (Ramos et al. 2003). Although in the present study, cognition-enhancing effects on executive function were observed after rolipram treatment in young monkeys, the possible cognition-impairing effects of rolipram on prefrontal cortex-dependent tests in aged monkeys should be further investigated.

Compared to PDE4 inhibition, the cognition-enhancing effects of PDE5 inhibition have not been studied as extensively. However, a growing number of studies have shown cognition-enhancing effects of PDE5-Is in multiple tests and in multiple species. PDE5-Is improved cognitive performance in object recognition and inhibitory and passive avoidance tasks (Baratti and Boccia 1999; Prickaerts et al. 2005; Prickaerts et al. 2004; Prickaerts et al. 2002b; Rutten et al. 2005; Shafiei et al. 2006; Singh and Parle 2003). In addition, the inhibition of PDE5 reversed memory deficits induced by scopolamine, diabetic neuropathy, or nitric oxide (NO) synthase inhibitors in rats (Devan et al. 2006; Devan et al. 2004; Patil et al. 2004; Prickaerts et al. 1997). To our knowledge, no literature exists on the possible cognition-enhancing effects of PDE5 inhibitors in nonhuman primates. Furthermore, the effects of PDE5 inhibition on prefrontal cortex-depending cognition, i.e., working memory and executive function, are unknown.

The underlying mechanisms of PDE-Is and cognition enhancement are still elusive, but several possible pathways have been described. Possible mechanisms of action for rolipram and sildenafil are based on the proposed underlying signaling pathways of LTP. Both cAMP and cGMP have been strongly implicated in hippocampal LTP (Frey et al. 1993). Activation of LTP-related signaling pathways of cAMP/PKA/cAMP response element-binding protein (CREB) and cGMP/protein kinase G (PKG)/CREB have been implicated as the underlying mechanisms for the cognition-enhancing effects of PDE4 and PDE5 inhibitors (Bernabeu et al. 1996; Blokland et al. 2006; Lu and Hawkins 2002; Prickaerts et al. 2002a; Rutten et al. 2007b). A very recent study suggested another pathway through which cGMP can influence cognitive processes. This study showed that the hippocampal NO/cGMP pathway directly stimulates the postsynaptic cAMP/PKA/ CREB pathway (Matsumoto et al. 2006). Alternatively, cGMP has also been found to maintain LTP via a presynaptic cGMP/PKG pathway (Zhuo et al. 1994). However, the present study involves prefrontal cortexdependent behavior, and it remains to be proven that the above mentioned hippocampal LTP mechanisms of synaptical strengthening are also applicable in the prefrontal cortex. Of note, the effects of rolipram on prefrontal cortex performance were explained via activation of the postsynaptic PKA pathway (Ramos et al. 2003). Thus, both cGMP and cAMP can activate cellular cascades resulting in CREB phosphorylation, which could induce long-lasting changes in neuronal signaling and may thereby explain the performance enhancement observed in the present study. 
Apart from LTP-related mechanisms of action, the effects of rolipram and sildenafil on prefrontal functioning in the OR may be explained by their stimulatory effect on neurotransmission. Because rolipram is independent of a specific receptor system, it is suggested that rolipram may ameliorate physiological abnormalities that occur secondary to alterations in dopaminergic, glutamatergic, serotonergic, and/or adrenergic transmission (Maxwell et al. 2004; Rutten et al. 2007a). Elevated cAMP levels are thought to excite noradrenergic and dopaminergic neurotransmitter systems (Schoffelmeer et al. 1985), thus enhancing their availability, hence also enhancing synaptic transmission. Similar to rolipram, sildenafil is a drug that is not linked to specific neurotransmitter systems. Modulatory activity of sildenafil was suggested on central dopaminergic pathways (Ferrari et al. 2002). Dopaminergic dysfunction in prefrontal cortex may subserve at least a component of the impaired OR/detour performance in deficit models (Jentsch et al. 1999a). Moreover, serotonin depletions of the prefrontal cortex in the common marmoset result in deficits in the acquisition of the OR task (Walker et al. 2006). Hence, activation of cGMP or cAMP may improve dopaminergic turnover and prefrontal functioning in the OR task. Thus far, it remains unclear which of these abovementioned mechanisms are involved in the prefrontal cortex and how they explain cognition enhancement by inhibition of PDEs in the OR task.

To summarize, previous research demonstrated the cognition- and largely memory-enhancing effects of PDE4 and PDE5 inhibition in rodents. The results from the current study extend these cognition-enhancing effects of PDE-Is in rodents to nonhuman primates. More specifically, rolipram and sildenafil improve OR performance, thus demonstrating that PDE4 and PDE5 inhibition enhance performance in a cognitive domain involving executive function (and attention) mediated by the prefrontal cortex.

Open Access This article is distributed under the terms of the Creative Commons Attribution NonCommercial License which permits any noncommercial use, distribution, and reproduction in any medium, provided the original author(s) and source are credited.

\section{References}

Barad M, Bourtchouladze R, Winder DG, Golan H, Kandel E (1998) Rolipram, a type IV-specific phosphodiesterase inhibitor, facilitates the establishment of long-lasting long-term potentiation and improves memory. Proc Natl Acad Sci USA 95:15020-15025

Baratti CM, Boccia MM (1999) Effects of sildenafil on long-term retention of an inhibitory avoidance response in mice. Behav Pharmacol 10:731-737
Bernabeu R, Schmitz P, Faillace MP, Izquierdo I, Medina JH (1996) Hippocampal cGMP and cAMP are differentially involved in memory processing of inhibitory avoidance learning. NeuroReport 7:585-588

Blokland A, Schreiber R, Prickaerts J (2006) Improving memory: a role for phosphodiesterases. Curr Pharm Des 12:2511-2523

Boess FG, Hendrix M, van der Staay FJ, Erb C, Schreiber R, van Staveren W, de Vente J, Prickaerts J, Blokland A, Koenig G (2004) Inhibition of phosphodiesterase 2 increases neuronal cGMP, synaptic plasticity and memory performance. Neuropharmacology 47:1081-1092

Brown VJ, Bowman EM (2002) Rodent models of prefrontal cortical function. Trends Neurosci 25:340-343

Campbell E, Edwards T (2006) Zaprinast consolidates long-term memory when administered to neonate chicks trained using a weakly reinforced single trial passive avoidance task. Behav Brain Res 169:181-185

Devan BD, Bowker JL, Duffy KB, Bharati IS, Jimenez M, SierraMercado D Jr., Nelson CM, Spangler EL, Ingram DK (2006) Phosphodiesterase inhibition by sildenafil citrate attenuates a maze learning impairment in rats induced by nitric oxide synthase inhibition. Psychopharmacology (Berl) 183:439-445

Devan BD, Sierra-Mercado D Jr, Jimenez M, Bowker JL, Duffy KB, Spangler EL, Ingram DK (2004) Phosphodiesterase inhibition by sildenafil citrate attenuates the learning impairment induced by blockade of cholinergic muscarinic receptors in rats. Pharmacol Biochem Behav 79:691-699

Diamond A, Zola-Morgan S, Squire LR (1989) Successful performance by monkeys with lesions of the hippocampal formation on $\mathrm{AB}$ and object retrieval, two tasks that mark developmental changes in human infants. Behav Neurosci 103:526-537

Egawa T, Mishima K, Matsumoto Y, Iwasaki K, Fujiwara M (1997) Rolipram and its optical isomers, phosphodiesterase 4 inhibitors, attenuated the scopolamine-induced impairments of learning and memory in rats. Jpn J Pharmacol 75:275-281

Ferrari F, Ottani A, Giuliani D (2002) Influence of sildenafil on central dopamine-mediated behaviour in male rats. Life Sci 70:1501-1508

Frey U, Huang YY, Kandel ER (1993) Effects of cAMP simulate a late stage of LTP in hippocampal CA1 neurons. Science 260:1661-1664

Grass H, Klotz T, Fathian-Sabet B, Berghaus G, Engelmann U, Kaferstein H (2001) Sildenafil (Viagra): is there an influence on psychological performance? Intern Urol Nephrol 32:409-412

Imanishi T, Sawa A, Ichimaru Y, Miyashiro M, Kato S, Yamamoto T, Ueki S (1997) Ameliorating effects of rolipram on experimentally induced impairments of learning and memory in rodents. Eur J Parmacol 321:273-278

Jentsch JD, Roth RH, Taylor JR (2000) Object retrieval/detour deficits in monkeys produced by prior subchronic phencyclidine administration: evidence for cognitive impulsivity. Biol Psychiatry 48:415-424

Jentsch JD, Taylor JR, Elsworth JD, Redmond DE Jr., Roth RH (1999a) Altered frontal cortical dopaminergic transmission in monkeys after subchronic phencyclidine exposure: involvement in frontostriatal cognitive deficits. Neuroscience 90: $823-832$

Jentsch JD, Taylor JR, Redmond DE Jr., Elsworth JD, Youngren KD, Roth RH (1999b) Dopamine D4 receptor antagonist reversal of subchronic phencyclidine-induced object retrieval/detour deficits in monkeys. Psychopharmacology (Berl) 142:78-84

Lipina SJ, Colombo JA (2001) Dissociated functional recovery in parkinsonian monkeys following transplantation of astroglial cells. Brain Res 911:176-180

Lu YF, Hawkins RD (2002) Ryanodine receptors contribute to cGMPinduced late-phase LTP and CREB phosphorylation in the hippocampus. J Neurophysiol 88:1270-1278 
Matsumoto Y, Unoki S, Aonuma H, Mizunami M (2006) Critical role of nitric oxide-cGMP cascade in the formation of cAMPdependent long-term memory. Learn Memory 13:35-44

Maxwell CR, Kanes SJ, Abel T, Siegel SJ (2004) Phosphodiesterase inhibitors: a novel mechanism for receptor-independent antipsychotic medications. Neuroscience 129:101-107

Palfi S, Ferrante RJ, Brouillet E, Beal MF, Dolan R, Guyot MC, Peschanski M, Hantraye P (1996) Chronic 3-nitropropionic acid treatment in baboons replicates the cognitive and motor deficits of Huntington's disease. J Neurosci 16:3019-3025

Patil CS, Singh VP, Kulkarni SK (2006) Modulatory effect of sildenafil in diabetes and electroconvulsive shock-induced cognitive dysfunction in rats. Pharmacol Rep 58:373-380

Patil CS, Singh VP, Singh S, Kulkarni SK (2004) Modulatory effect of the PDE-5 inhibitor sildenafil in diabetic neuropathy. Pharmacology 72:192-195

Prickaerts J, de Vente J, Honig W, Steinbusch HW, Blokland A (2002a) cGMP, but not cAMP, in rat hippocampus is involved in early stages of object memory consolidation. Eur J Pharmacol 436:83-87

Prickaerts J, Ș1k A, van der Staay FJ, de Vente J, Blokland A (2005) Dissociable effects of acetylcholinesterase inhibitors and phosphodiesterase type 5 inhibitors on object recognition memory: acquisition versus consolidation. Psychopharmacology (Berl) 177:381-390

Prickaerts J, Ș1k A, van Staveren WC, Koopmans G, Steinbusch HW, van der Staay FJ, de Vente J, Blokland A (2004) Phosphodiesterase type 5 inhibition improves early memory consolidation of object information. Neurochem Int 45:915-928

Prickaerts J, Steinbusch HW, Smits JF, de Vente J (1997) Possible role of nitric oxide-cyclic GMP pathway in object recognition memory: effects of 7-nitroindazole and zaprinast. Eur J Pharmacol 337:125-136

Prickaerts J, van Staveren WC, Ș1k A, Markerink-van Ittersum M, Niewohner U, van der Staay FJ, Blokland A, de Vente J (2002b) Effects of two selective phosphodiesterase type 5 inhibitors, sildenafil and vardenafil, on object recognition memory and hippocampal cyclic GMP levels in the rat. Neuroscience 113:351-361

Ramos BP, Birnbaum SG, Lindenmayer I, Newton SS, Duman RS, Arnsten AF (2003) Dysregulation of protein kinase A signaling in the aged prefrontal cortex: new strategy for treating age-related cognitive decline. Neuron 40:835-845

Rodefer JS, Murphy ER, Baxter MG (2005) PDE10A inhibition reverses subchronic PCP-induced deficits in attentional setshifting in rats. Eur J Neurosci 21:1070-1076

Roitberg BZ, Emborg ME, Sramek JG, Palfi S, Kordower JH (2002) Behavioral and morphological comparison of two nonhuman primate models of Huntington's disease. Neurosurgery 50: 137-145 (discussion 145-146)

Rose GM, Hopper A, De Vivo M, Tehim A (2005) Phosphodiesterase inhibitors for cognitive enhancement. Curr Pharm Des 11: 3329-3334

Rutten K, Lieben C, Smits L, Blokland A (2007a) The PDE4 inhibitor rolipram reverses object memory impairment induced by acute tryptophan depletion in the rat. Psychopharmacology (Berl) 192:275-282

Rutten K, Prickaerts J, Blokland A (2006) Rolipram reverses scopolamine-induced and time-dependent memory deficits in object recognition by different mechanisms of action. Neurobiol Learn Mem 85:132-138
Rutten K, Prickaerts J, Hendrix M, van der Staay FJ, Ş.k A, Blokland A (2007b) Time-dependent involvement of cAMP and cGMP in consolidation of object memory: studies using selective phosphodiesterase type 2, 4 and 5 inhibitors. Eur J Pharmacol 558:107-112

Rutten K, Vente JD, S.1k A, Ittersum MM, Prickaerts J, Blokland A (2005) The selective PDE5 inhibitor, sildenafil, improves object memory in Swiss mice and increases cGMP levels in hippocampal slices. Behav Brain Res 164:11-16

Schneider JS, Roeltgen DP (1993) Delayed matching-to-sample, object retrieval, and discrimination reversal deficits in chronic low dose MPTP-treated monkeys. Brain Res 615:351-354

Schoffelmeer AN, Wardeh G, Mulder AH (1985) Cyclic AMP facilitates the electrically evoked release of radiolabelled noradrenaline, dopamine and 5-hydroxytryptamine from rat brain slices. Naunyn-Schmiedeberg's Arch Pharmacol 330:74-76

Schultheiss D, Muller SV, Nager W, Stief CG, Schlote N, Jonas U, Asvestis C, Johannes S, Munte TF (2001) Central effects of sildenafil (Viagra) on auditory selective attention and verbal recognition memory in humans: a study with event-related brain potentials. World J Urol 19:46-50

Shafiei M, Mahmoudian M, Rostami P, Nemati F (2006) Effect of sildenafil (Viagra) on memory retention of a passive avoidance response in rats. Acta Physiol Hung 93:53-59

Singh N, Parle M (2003) Sildenafil improves acquisition and retention of memory in mice. Indian J Physiol Pharmacol 47:318-324

Taylor JR, Elsworth JD, Roth RH, Sladek JR Jr., Redmond DE Jr. (1990a) Cognitive and motor deficits in the acquisition of an object retrieval/detour task in MPTP-treated monkeys. Brain 113 (Pt 3):617-637

Taylor JR, Roth RH, Sladek JR Jr., Redmond DE Jr. (1990b) Cognitive and motor deficits in the performance of an object retrieval task with a barrier-detour in monkeys (Cercopithecus aethiops sabaeus) treated with MPTP: long-term performance and effect of transparency of the barrier. Behav Neurosci 104:564-576

Uylings HB, Groenewegen HJ, Kolb B (2003) Do rats have a prefrontal cortex? Behav Brain Res 146:3-17

van Staveren WC, Steinbusch HW, Markerink-van Ittersum M, Behrends S, de Vente J (2004) Species differences in the localization of cGMP-producing and NO-responsive elements in the mouse and rat hippocampus using cGMP immunocytochemistry. Eur J Neurosci 19:2155-2168

Walker SC, Mikheenko YP, Argyle LD, Robbins TW, Roberts AC (2006) Selective prefrontal serotonin depletion impairs acquisition of a detour-reaching task. Eur J Neurosci 23:3119-3123

Wilkinson LS, Dias R, Thomas KL, Augood SJ, Everitt BJ, Robbins TW, Roberts AC (1997) Contrasting effects of excitotoxic lesions of the prefrontal cortex on the behavioural response to Damphetamine and presynaptic and postsynaptic measures of striatal dopamine function in monkeys. Neuroscience 80:717-730

Zhang HT, Huang Y, Suvarna NU, Deng C, Crissman AM, Hopper AT, De Vivo M, Rose GM, O'Donnell JM (2005) Effects of the novel PDE4 inhibitors MEM1018 and MEM1091 on memory in the radial-arm maze and inhibitory avoidance tests in rats. Psychopharmacology (Berl) 179:613-619

Zhang HT, O'Donnell JM (2000) Effects of rolipram on scopolamineinduced impairment of working and reference memory in the radial-arm maze tests in rats. Psychopharmacology (Berl) 150:311-316

Zhuo M, Hu Y, Schultz C, Kandel ER, Hawkins RD (1994) Role of guanylyl cyclase and cGMP-dependent protein kinase in longterm potentiation. Nature 368:635-639 